\title{
Magnetic domains in ErCrO4 studied by 3D neutron depolarization
}

DOI:

10.1016/j.physb.2004.03.073

\section{Document Version}

Final published version

Link to publication record in Manchester Research Explorer

\section{Citation for published version (APA):}

Jimenez-Melero, E., Kraan, W. H., van Dijk, N. H., Gubbens, P. C. M., Isasi, J., \& Saez-Puche, R. (2004).

Magnetic domains in ErCrO4 studied by 3D neutron depolarization. Physica, 350(1-2), e293-e296.

https://doi.org/10.1016/j.physb.2004.03.073

\section{Published in:}

Physica

\section{Citing this paper}

Please note that where the full-text provided on Manchester Research Explorer is the Author Accepted Manuscript or Proof version this may differ from the final Published version. If citing, it is advised that you check and use the publisher's definitive version.

\section{General rights}

Copyright and moral rights for the publications made accessible in the Research Explorer are retained by the authors and/or other copyright owners and it is a condition of accessing publications that users recognise and abide by the legal requirements associated with these rights.

\section{Takedown policy}

If you believe that this document breaches copyright please refer to the University of Manchester's Takedown Procedures [http://man.ac.uk/04Y6Bo] or contact uml.scholarlycommunications@manchester.ac.uk providing relevant details, so we can investigate your claim.

\section{OPEN ACCESS}




\title{
Magnetic domains in $\mathrm{ErCrO}_{4}$ studied by 3D neutron depolarization
}

\author{
E. Jiménez ${ }^{\mathrm{a}}$, W.H. Kraan ${ }^{\mathrm{b}, *}$, N.H. van Dijk ${ }^{\mathrm{b}}$, P.C.M. Gubbens ${ }^{\mathrm{b}}$, \\ J. Isasi ${ }^{\mathrm{a}}$, R. Sáez-Puche ${ }^{\mathrm{a}}$ \\ ${ }^{a}$ Departmento Q. Inorgánica, Fac. C. Quimicas, Universidad Complutense de Madrid, Ciudad Universitaria, E-28040 Madrid, Spain \\ ${ }^{\mathrm{b}}$ Interfacultair Reactor Instituut TU Delft, Mekelweg 15, 2629 JB Delft, The Netherlands
}

\begin{abstract}
We performed temperature-dependent $3 \mathrm{D}$ neutron-depolarisation measurements on an $\mathrm{ErCrO}_{4}$ powder sample to study the ferromagnetic order below $T_{\mathrm{C}} \simeq 15 \mathrm{~K}$. From the determinant of the depolarisation matrix, the domain size is calculated as a function of temperature. It is discussed in terms of the applied magnetic field and field history.

(C) 2004 Elsevier B.V. All rights reserved.
\end{abstract}

Keywords: Polarized neutrons; 3D polarization analysis; Magnetic domains

\section{Introduction}

$\mathrm{RCrO}_{4}$ oxides $(\mathrm{R}=\mathrm{Nd}-\mathrm{Lu}$ and $\mathrm{Y})$ crystallize into the zircon-type structure (space group I $4_{1} /$ amd) of tetragonal symmetry with 4 formula units per unit cell [1]. Most of them, namely from Gd to Tm and Y, present ferromagnetic interactions at low temperatures [2]. Therefore, they are ideal systems to assess the influence of the rare earth intrinsic magnetic anisotropy on the average domain size. The $\mathrm{Cr}^{5+}$ ion is considered to be magnetically isotropic.

We have focused on the $\mathrm{ErCrO}_{4}$ compound. Susceptibility and magnetization measurements indicate the presence of ferromagnetic interactions below $15 \mathrm{~K}$. The analysis of the neutron-diffrac-

\footnotetext{
*Corresponding author.

E-mail address: W.H.Kraan@IRI.TUDELFT.NL (W.H. Kraan).
}

tion pattern at $2 \mathrm{~K}$ reveals a ferromagnetic alignment of both sublattices in the $a b$-plane, the ordered magnetic moments being $5.09 \mu_{\mathrm{B}}$ for the $\mathrm{Er}^{3+}$ ions and $0.91 \mu_{\mathrm{B}}$ for the $\mathrm{Cr}^{5+}$ ions [3]. This means an average of $5.2 \mu_{\mathrm{B}}$ per formula unit and it corresponds to a bulk induction $\mu_{0} M_{\mathrm{S}}=0.78 \mathrm{~T}$ at $2 \mathrm{~K}$. The magnetic moments of both sublattices lie in the basal plane, so that $90^{\circ}$-domain walls are expected.

\section{Sample and measuring technique}

Fig. 1 is a SEM micrograph of $\mathrm{ErCrO}_{4}$ powder. The appearance at $10 \times$ higher magnification is very similar. This powder was compressed into a cylindrical volume of diameter $12 \mathrm{~mm}$, thickness $3 \mathrm{~mm}$, and weight $0.65 \mathrm{~g}$. This corresponds to a volume filling fraction $f=0.25$. To improve the 


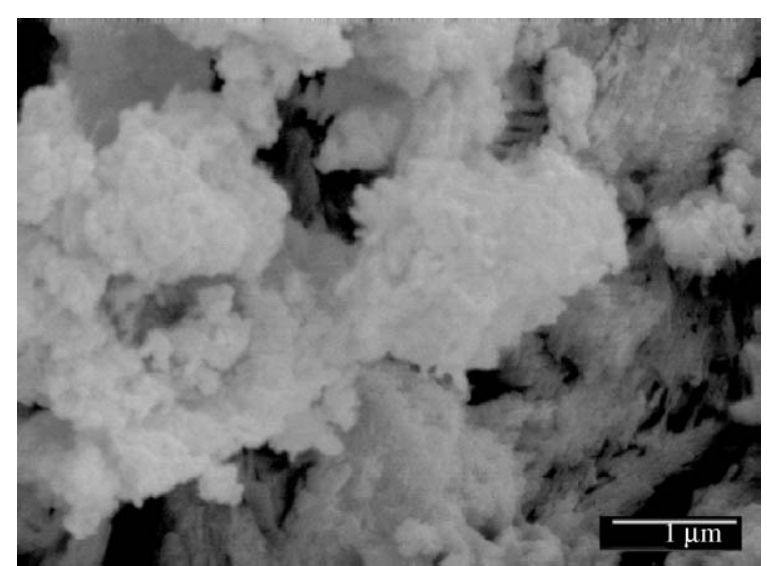

Fig. 1. SEM micrograph of $\mathrm{ErCrO}_{4}$.

thermal conductivity and contact to the environment the sample was soaked in paraffine. The sample was probed by a polarized monochromatic neutron beam. The incoming neutron-polarization vector can be adjusted parallel to any direction of the $x, y, z$-coordinate system, $x$ being along the beam propagation. The transmitted polarization for each direction is analyzed independently, to obtain a $(3 \times 3)$ depolarization matrix, denoted $\mathbf{D}$. The sample, when ferromagnetic, will depolarize the beam, i.e. it will reduce the determinant of this matrix.

The depolarization matrix $\mathbf{D}$ generally probes the spatial variation of the local magnetic induction $\vec{B}(x, y, z)$ oriented perpendicular to the polarization $\vec{P}$ in the sample. The determinant of this matrix is given by [4]

$\operatorname{det} \mathbf{D}=\exp \left(-2 c \lambda^{2} f L_{x} \xi\right)$,

where $c=21.5 \times 10^{28} \mathrm{~T}^{-2} \mathrm{~m}^{-4}$ is a constant, $\lambda=$ $0.2 \mathrm{~nm}$ is the neutron wavelength, $f=0.25$ is the filling fraction, and $L_{x}=3.0 \mathrm{~mm}$ is the sample length in the beam direction. For spherical magnetic domains of radius $R$ and randomly oriented magnetization, the correlation parameter $\xi$ is given by [4]

$$
\begin{aligned}
\xi & =\left\langle\int_{0}^{L_{x}} \Delta \vec{B}(x, y, z) \cdot \Delta \vec{B}\left(x+x^{\prime}, y, z\right) \mathrm{d} x^{\prime}\right\rangle \\
& =\mu_{0}^{2} M_{\mathrm{s}}^{2} R / 2,
\end{aligned}
$$

where $\langle\cdots\rangle$ represents a spatial average over the sample volume illuminated by the $6 \times 6 \mathrm{~mm}^{2}$ cross section of the neutron beam. $M_{\mathrm{S}}$ is the saturation magnetization that depends on the temperature below the Curie temperature $T_{\mathrm{C}}$. Hence, the domain radius $R$ can be written as

$R=-\ln (\operatorname{det} \mathbf{D}) /\left(c \lambda^{2} L_{x} f \mu_{0}^{2} M_{\mathrm{s}}^{2}\right)$.

In case the sample has no net magnetization, the matrix $\mathbf{D}$ is diagonal. If the sample is magnetized by an external magnetic field, or owing to remanence, the polarization vector will precess away from its initial direction at an angle $\phi=$ $\eta \sqrt{c} \lambda f L_{x} \mu_{0}\langle M\rangle$ around the direction of the mean magnetization, where $\eta=\frac{1}{2}$ is a reduction factor that accounts for the stray fields of the magnetized sample [5]. Then, non-zero elements appear outside the diagonal of $\mathbf{D}$. We applied a field parallel to $z$, so the mean magnetization is expected in that direction. Then, the rotation can be calculated from $\phi=\arctan \left[\left(D_{x y}-D_{y x}\right) /\left(D_{x x}+D_{y y}\right)\right]$. The mean magnetization is calculated by

$\mu_{0}\langle M\rangle=\phi /\left(\eta \sqrt{c} \lambda f L_{x}\right)$.

\section{Results}

Fig. 2 shows the results obtained during field warming (FW) after zero-field cooling (ZFC) and subsequent field cooling (FC). The field was $62 \mathrm{~A} / \mathrm{cm}(77 \mathrm{Oe})$. Fig. $2 \mathrm{a}$ gives the determinant, normalized to its value above $T_{\mathrm{C}}$ (equal to 0.72 for this field). The results for the individual diagonal elements $D_{x x}, D_{y y}$ and $D_{z z}$ suggest that the magnetization directions are isotropically distributed. Fig. $2 \mathrm{~b}$ gives the mean magnetization $\mu_{0}\langle M(T)\rangle$ as found from the rotation $\phi$ of the polarization vector around the $z$-axis, using Eq. (4). The rotation found above $T_{\mathrm{C}}$, attributed to the field of the magnetizing coil alone, is subtracted. During FW after ZFC the magnetization ( + signs) is relatively small, but it increases on approaching $T_{\mathrm{C}}$, owing to a decrease of the magneto-crystalline anisotropy. The magnetization in the subsequent FC (circles) becomes much higher. Measuring in fields of 25 and $50 \mathrm{~A} / \mathrm{cm}$ (32 and $64 \mathrm{Oe})$, we find that $\mu_{0}\langle M(T)\rangle$ is proportional to the field at all temperatures. 

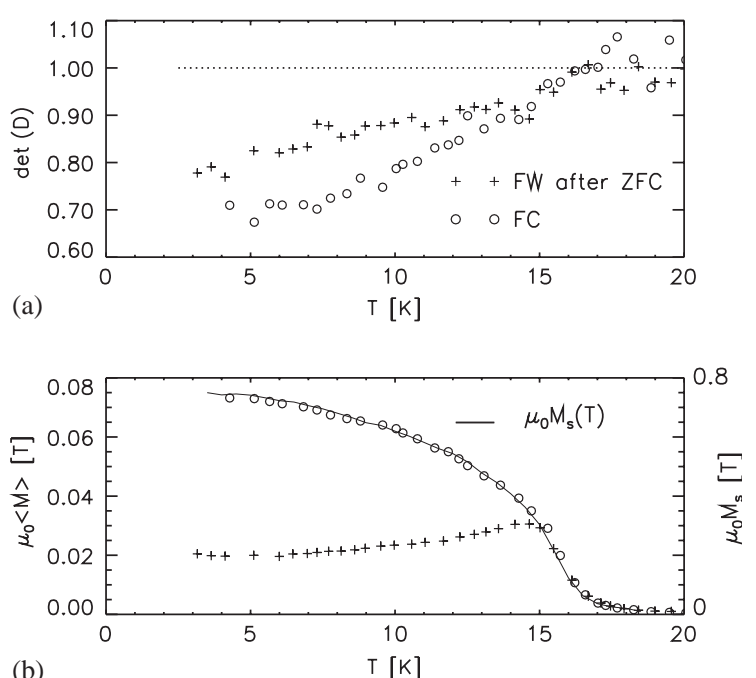

(b)

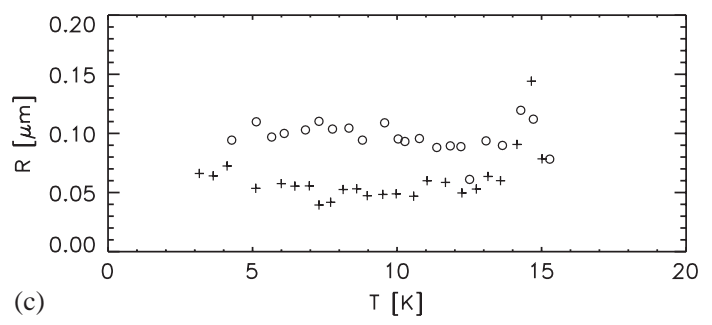

Fig. 2. Depolarization in $\mathrm{ErCrO}_{4}$ in a field along $z$ of $62 \mathrm{~A} / \mathrm{cm}$ (77 Oe): (a) determinant; (b) mean magnetization $\mu_{0}\langle M\rangle$ calculated according to Eq. (4) (left scale) and spontaneous magnetization $\mu_{0} M_{\mathrm{s}}(T)$ (right scale) used in Eq. (3) to calculate the domain radius (c).

Therefore, in the calculation of the domain radius according to Eq. (3), we take $\mu_{0} M_{\mathrm{s}}(T)$ proportional to $\phi(T)$, normalized such that at $2 \mathrm{~K} \mu_{0} M_{\mathrm{s}}=0.78 \mathrm{~T}$, known from both magnetization measurement at $2 \mathrm{~K}$ in fields up to $0.5 \mathrm{~T}$ and from the refined neutron-diffraction pattern at $2 \mathrm{~K}$ [3]. This assumption is represented by the solid line in Fig. 2b. The result for $R$ is shown in Fig. 2c. In FC through $T_{\mathrm{C}}$, we find $R$ to have a constant value of $0.10 \mu \mathrm{m}$. This is comparable to the size of the smallest entities visible in Fig. 1, but much smaller than the average powder grain size. Strictly, Eq. (3) holds in the absence of magnetization; however, when $\langle M\rangle \ll M_{\mathrm{s}}$, this equation is valid with good precision.

The domain radii found are collected in Table 1. For all fields the domain radius hardly depends on
Table 1

Average domain radius (standard deviation)

\begin{tabular}{lll}
\hline$H(\mathrm{~A} / \mathrm{cm})$ & $\langle R\rangle_{4<T<14 \mathrm{~K}}(\mu \mathrm{m})$ & \\
\cline { 2 - 3 } & FW after ZFC & FC \\
\hline 0 & $0.020(0.005)$ & $0.019(0.005)$ \\
25 & $0.023(0.009)$ & $0.068(0.010)$ \\
50 & $0.027(0.009)$ & $0.070(0.010)$ \\
64 & $0.055(0.008)$ & $0.097(0.012)$ \\
\hline
\end{tabular}

temperature. This means that the domain structure is established on passing $T_{\mathrm{C}}$ and does not change during further cooling.

In summary, from 3D neutron depolarization in $\mathrm{ErCrO}_{4}$ we confirmed the existence of ferromagnetic order in this compound below a Curie temperature $T_{\mathrm{C}} \simeq 16 \mathrm{~K}$. We can derive a mean domain radius $R$; it remains constant as a function of temperature, at given field history. For all fields applied it is found that $R$ during $\mathrm{FW}$ after $\mathrm{ZFC}$ is smaller than during FC. This means that in ZFC through $T_{\mathrm{C}}$ some domain structure is established inside the grains which does not change during further ZFC. The domain structure does not change significantly when a field is switched on at $3 \mathrm{~K}$, owing to the strong magnetic anisotropy. However, when the field is switched on before going through $T_{\mathrm{C}}$, the magnetization inside the grains can respond to the field, because the anisotropy is weak just below $T_{\mathrm{C}}$. Hence, domains with magnetization along the preferred direction closest to the field direction are formed. This domain structure prevails down to $3 \mathrm{~K}$.

\section{Acknowledgements}

We thank E. Urones and D. Avila from the Centro de Microscopía Luis Bru, UCM for their help in the Electron Microscopy study on the $\mathrm{ErCrO}_{4}$ sample.

\section{References}

[1] G. Buisson, F. Bertaut, J. Mareschal, C.R. Acad. Sci. Paris 259 (1964) 411. 
[2] H. Walter, H.G. Khale, K. Mulder, H.C. Schopper, H. Schwarz, Int. J. Magn. 5 (1973) 129.

[3] R. Sáez-Puche, E. Jiménez, M.T. Fernández, J.L. GarcíaMuñoz, J. Solid State Chem. 171 (2003) 161.
[4] R. Rosman, M.Th. Rekveldt, Phys. Rev. B 43 (1991) 8437.

[5] N.H. van Dijk, et al., Physica B 267-268 (1999) 88. 